\title{
Modulation of $\mathrm{Na}^{+} /$alanine cotransport in liver sinusoidal membrane vesicles by internal divalent cations
}

\author{
Thomas W. Simmons ${ }^{1}$, Richard H. Moseley ${ }^{2}$, James L. Boyer ${ }^{3}$ \\ and Nazzareno Ballatori ${ }^{1}$ \\ 'Department of Biophysics, Environmental Health Sciences Center, University of Rochester School of Medicine, Rochester, NY, \\ ${ }^{2}$ Department of Medicine, University of Michigan School of Medicine and Veterans Administration Medical Center, Ann Arbor, MI \\ and ${ }^{3}$ Department of Medicine and Liver Center, Yale University School of Medicine, New Haven, CT (U.S.A.)
}

(Received 17 November 1989)

Key words: Alanine transport; Sodium ion cotransport; Membrane vesicle; Divalent cation inhibition; Magnesium; Calcium; (Rat liver)

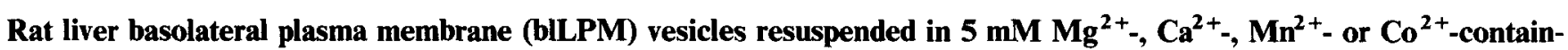
ing media exhibited a markedly lower rate of $\mathrm{Na}^{+}$-stimulated $\mathrm{L}$-alanine transport. Divalent cation inhibition of $\mathrm{L}$-alanine uptake was dose dependent, and was observed only when the vesicles were pre-loaded with the divalent cations. The presence or absence of the metal ions in the extravesicular incubation media had no effect on L-alanine transport. Conversely, pretreatment of the vesicles with $0.2 \mathrm{mM}$ of either EGTA or EDTA resulted in higher initial rates of L-alanine transport. This stimulation was overcome by addition of excess divalent cation to the vesicle suspension solution. Since these bILPM vesicles are primarily oriented right-side-out, the divalent cation inhibition of $L$-alanine transport appears to be a result of their interaction with cytosolic components of the cell membrane. Total $\mathrm{Na}^{+}$flux as measured with ${ }^{22} \mathrm{Na}^{+}$was not affected by intravesicular $5 \mathrm{mM} \mathrm{Mg}^{2+}$ or $\mathrm{Ca}^{2+}$, indicating that the inhibition was not due to dissipation of the $\mathrm{Na}^{+}$gradient. These observations suggest that intracellular divalent cations may serve to modulate L-alanine transport across the liver cell plasma membrane.

\section{Introduction}

Divalent metal cations such as $\mathrm{Mg}^{2+}, \mathrm{Ca}^{2+}, \mathrm{Mn}^{2+}$, and $\mathrm{Co}^{2+}$ serve as co-factors in approximately one-third of all enzyme systems, including membrane-associated enzymes; they serve to chelate metabolic intermediates (e.g. ATP and ADP, $\alpha$-amino acids, and biogenic amines); and they may function as second or third messengers in cellular signal transduction [1]. Divalent cations also bind to anionic sites on the polar head groups of neighboring membrane phospholipids, thereby decreasing the mobility of phospholipids and increasing membrane rigidity $[2,3]$. Recent evidence indicates that divalent cations may also interact directly with integral membrane proteins to alter their structural or catalytic functions. The $\mathrm{K}^{+} / \mathrm{Cl}^{-}$co-transporter of the sheep red blood cell plasma membrane has been shown to possess a binding site for divalent metal ions, which when

Correspondence: N. Ballatori, Department of Biophysics, Box EHSC, University of Rochester School of Medicine, Rochester, NY 14642, U.S.A. occupied inactivates the $\mathrm{K}^{+} / \mathrm{Cl}^{-}$co-transporter [4]. Similarly, the activity of the electroneutral $\mathrm{K}^{+} / \mathrm{H}^{+}$ exchanger in mitochondria appears to be controlled by the concentration of $\mathrm{Mg}^{2+}$ in the mitochondrial matrix [5]. In intestinal brush-border membrane vesicles, the $\mathrm{Na}^{+}$-coupled transport of bile acids, glucose, and valine was significantly reduced by the presence of intravesicular $\mathrm{Ca}^{2+}[6,7]$. Our previous studies on the effects of $\mathrm{Ca}^{2+}$ on liver plasma membrane fluidity and $\mathrm{Na}^{+}$-coupled taurocholate transport showed that intravesicular concentrations of calcium as low as $0.2 \mathrm{mM}$ were able to significantly inhibit $\mathrm{Na}^{+}$-coupled taurocholate transport [8].

Despite the wide range of divalent cation-induced alterations of membrane structure and function, the effects of divalent cations on transport processes in membrane vesicles are not well characterized, even though chloride salts of metals are routinely added to solutions used in studies with vesicles. The present study is an outgrowth of attempts to define optimal conditions for studying amino acid transport in rat liver basolateral plasma membrane (blLPM) vesicles. The results reveal that inclusion of $\mathrm{Mg}^{2+}$ or $\mathrm{Ca}^{2+}$ in the 
membrane suspension solution inhibits $\mathrm{Na}^{+}$-coupled alanine transport. Although the nature of the inhibition is not known, this process has implications for our understanding of hepatic amino acid transport. In addition, our findings should discourage routine addition of divalent cations to vesicle suspension solutions.

\section{Materials and Methods}

Preparation of rat liver plasma membrane vesicles. The methods for isolating canalicular (CLPM) and blLPM subfractions, as well as their morphologic and biochemical characterization are described in detail elsewhere $[9,10]$. In brief, a 'mixed LPM' subfraction was first separated out of a 'crude nuclear pellet' by rate zonal floatation $(44 / 36.5 \%, \mathrm{w} / \mathrm{w}$, sucrose density interface) in the TZ-28 (Sorvall) zonal rotor. After tight homogenization (Type B Dounce homogenizer, 75 up and down strokes) the vesiculated CLPM and blLPM were separated by high speed centrifugation $\left(195000 \times g_{\text {ave }}\right.$ for 3 h) of the mixed LPM through a 3-step sucrose gradient $(31,34$, and $38 \%, w / w)$, and the membranes were collected at $105000 \times g_{\text {ave }}$ for $60 \mathrm{~min}$. Freshly isolated membranes were divided into aliquots which were resuspended in $300 \mathrm{mM}$ sucrose and $20 \mathrm{mM}$ Hepes-Tris (pH 7.5) containing either no additions (controls), divalent cations (i.e., $5 \mathrm{mM} \mathrm{CaCl}, \mathrm{MgCl}_{2}, \mathrm{MnCl}_{2}, \mathrm{CoCl}_{2}$ ), chelating agents (i.e., $0.2 \mathrm{mM}$ EDTA, EGTA), or both. The exact composition of the suspension media is given in the figure and table legends of the individual experiments. The membranes were stored at $-80^{\circ} \mathrm{C}$ until used.

Freeze-fracture analysis revealed that approx. $73 \%$ of blLPM vesicles exhibited 'right-side-out' configuration, in which the extravesicular membrane face corresponds to the sinusoidal surface in vivo [11].

The purity of each membrane preparation was routinely analyzed by measurement of $\mathrm{Na}^{+} / \mathrm{K}^{+}$-ATPase and $\mathrm{Mg}^{2+}$-ATPase activities [12], and $\gamma$-glutamyltransferase activity [13]. Protein was determined according to Lowry et al. [14], using bovine serum albumin as a standard.

Transport measurements. Frozen membrane suspensions were quickly thawed by immersion in a $40^{\circ} \mathrm{C}$ water bath, diluted to the desired protein concentration, and passed repeatedly (10 times) through a 25 gauge needle. Uptake of $\mathrm{L}-\left[{ }^{3} \mathrm{H}\right]$ alanine was measured by a rapid Millipore filtration technique. Membrane suspensions $(50-100 \mu \mathrm{g}$ of protein in $20 \mu \mathrm{l})$ were preincubated at $25^{\circ} \mathrm{C}$ for $5-10 \mathrm{~min}$. Uptake studies were initiated by the addition of $80 \mu 1$ of incubation medium also prewarmed to $25^{\circ} \mathrm{C}$, containing $\mathrm{L}-\left[{ }^{3} \mathrm{H}\right] \mathrm{alanine}$. The exact composition of the incubation media is given in the figure and table legends of the individual experiments. Transport was terminated by the addition of $3 \mathrm{ml}$ of ice-cold stop solution; $100 \mathrm{mM} \mathrm{NaCl}, 100 \mathrm{mM}$ sucrose,
$0.2 \mathrm{mM} \mathrm{CaCl}_{2}, 5 \mathrm{mM} \mathrm{MgCl}_{2}$, and $20 \mathrm{mM}$ Hepes-Tris (pH 7.5). Membrane vesicle-associated ligand was separated from free ligand by immediate rapid filtration (1 $\mathrm{ml} \cdot \mathrm{s}^{-1}$ ) through a $0.45 \mu \mathrm{m}$ Millipore filter (HAWP). The filter was washed twice with $3 \mathrm{ml}$ of stop solution, dissolved in $4.5 \mathrm{ml}$ of Safety-Count (Research Products International, Mount Prospect, IL) and counted in a Packard TRI-CARB 4350 liquid scintillation counter. Uptake of ${ }^{22} \mathrm{Na}$ was measured by a similar method except that filters were dissolved in Redisolv HP (Beckman Instruments, Palo Alto, CA) and counted in a Beckman LS 1801 liquid scintillation counter. Nonspecific binding of isotope to the membranes was determined in each experiment by addition of cold stop solution to $20 \mu 1$ of membrane suspension prior to addition of incubation solution. This blank was subtracted from all determinations. Unless otherwise indicated, all incubations were performed in triplicate and all observations confirmed with three or more separate membrane preparations.

All values are expressed as mean \pm S.D. The data were compared by the paired $t$-test and differences were considered to be statistically significant at $P<0.05$.

Metal analysis. Total calcium levels in buffers and membrane suspensions were determined by atomic absorption spectroscopy according to Christensen [15].

Chemicals. L- $\left[3-{ }^{3} \mathrm{H}\right]$ alanine $\left(84 \mathrm{Ci} \cdot \mathrm{mmol}^{-1}\right)$ was obtained from New England Nuclear, Boston, MA (U.S.A.); and ${ }^{22} \mathrm{Na}$ from Amersham Corp., Arlington Heights, IL (U.S.A.). All other chemicals and reagents were purchased from either Sigma Chemical Co., St. Louis, MO (U.S.A.), Baker Chemical Co., Phillipsburg, NJ (U.S.A.), or Schwarz/Mann Inc., Spring Valley, NY (U.S.A.).

\section{Results}

The time course of $\mathrm{L}-\left[^{3}-\mathrm{H}\right]$ alanine uptake into blLPM vesicles was examined in the absence (Fig. $1 \mathrm{~A}$ and $\mathrm{B}$ ) and presence (Fig. 1C and D) of $5 \mathrm{mM}$ intravesicular $\mathrm{MgCl}_{2}$. The concentration of $\mathrm{MgCl}_{2}$ in the incubation media (extravesicular space) was also varied from 0 to 5 $\mathrm{mM}$ (Fig. 1). In the absence of $\mathrm{Mg}^{2+}$ from both the intravesicular and extravesicular media, transport of L-alanine was stimulated by a $\mathrm{Na}^{+}$gradient and an overshoot was observed (Fig. 1A). Comparable results have been reported in similar membrane preparations $[10,16]$. The presence of $5 \mathrm{mM} \mathrm{Mg}^{2+}$ in the incubation media (Fig. 1B), did not influence L-alanine uptake by the blLPM vesicles. However, when the vesicles were preloaded with $\mathrm{Mg}^{2+}$ (Fig. 1C and D), the $\mathrm{Na}^{+}$-gradient dependent transport of $\mathrm{L}$-alanine was significantly decreased, regardless of the extravesicular concentration of $\mathrm{Mg}^{2+}$. The $60 \mathrm{~min}$ uptakes (equilibrium values) of L-alanine were similar under all conditions suggesting that vesicle size was unaffected by $\mathrm{Mg}^{2+}$ (Fig. 1). 


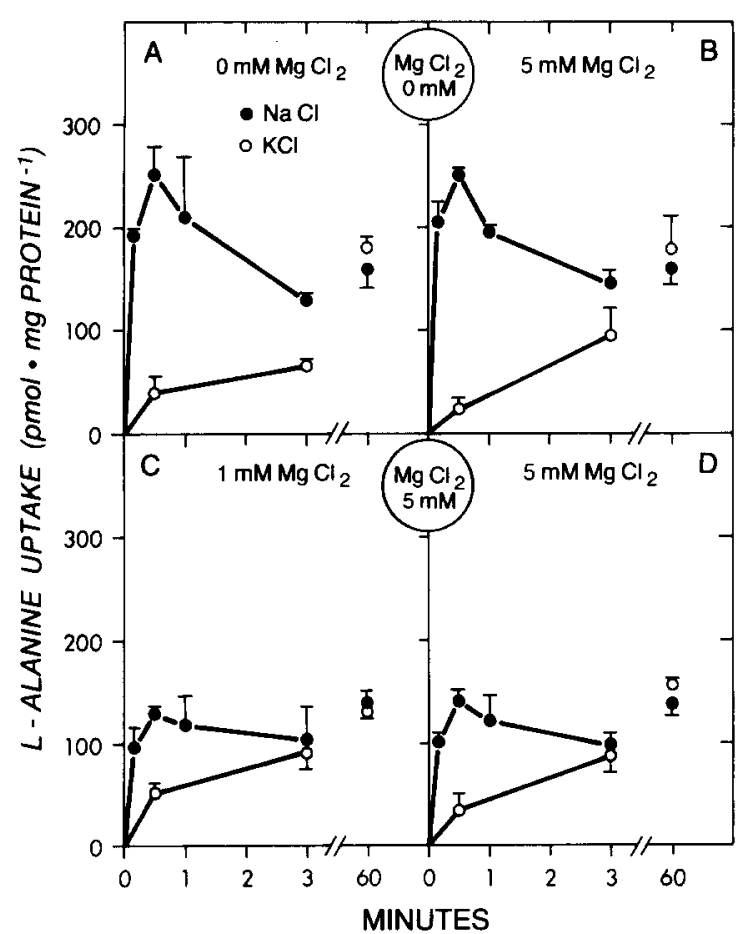

Fig. 1. Effects of intra- and extravesicular $\mathrm{Mg}^{2+}$ on L-alanine uptake by bILPM vesicles. Freshly isolated membrane vesicles were divided into two aliquots: one aliquot (panels $\mathrm{A}$ and $\mathrm{B}$ ) was resuspended in a solution containing $300 \mathrm{mM}$ sucrose and $20 \mathrm{mM}$ Hepes-Tris ( $\mathrm{pH} 7.5$ ) without added $\mathrm{MgCl}_{2}$; while the other aliquot (panels $\mathrm{C}$ and $\mathrm{D}$ ) was resuspended in $300 \mathrm{mM}$ sucrose, $20 \mathrm{mM}$ Hepes-Tris (pH 7.5) and 5 $\mathrm{mM} \mathrm{MgCl} 2$. Uptake of $0.2 \mathrm{mM} \mathrm{L}-\left[{ }^{3} \mathrm{H}\right]$ alanine was measured at $25^{\circ} \mathrm{C}$ in an incubation solution containing $100 \mathrm{mM}$ of either $\mathrm{NaCl}(\bullet)$ or $\mathrm{KCl}(\mathrm{O}), 20 \mathrm{mM}$ Hepes-Tris (pH 7.5) and with (panels B and D) or without (panels $\mathrm{A}$ and $\mathrm{C}$ ) $\mathrm{MgCl}_{2}$, to give the extravesicular $\mathrm{MgCl}_{2}$ concentrations indicated in the figure. Isoosmolarity of the incubation solutions was maintained with sucrose. Results are shown for one representative experiment of three with each data point (mean \pm S.D.) performed in triplicate.

Furthermore, the effects of $\mathrm{Mg}^{2+}$ were exclusively on the $\mathrm{Na}^{+}$-coupled uptake mechanism, since uptake in the presence of $\mathrm{a} \mathrm{K}^{+}$gradient was unaffected.

The inhibitory effects of $\mathrm{Mg}^{2+}$ on L-alanine uptake by the blLPM vesicles were mimicked by similar concentrations of $\mathrm{Ca}^{2+}$ (Fig. 2). Thus, in $\mathrm{CaCl}_{2}$-preloaded blLPM vesicles (Fig. $2 \mathrm{C}$ and D) $\mathrm{Na}^{+}$-stimulated uptake of L-alanine was significantly lower than in control vesicles (Fig. $2 \mathrm{~A}$ and B), while extravesicular $\mathrm{Ca}^{2+}$ did not appear to influence alanine transport.

To determine if the inhibitory effect of $\mathrm{Mg}^{2+}$ was dose-dependent, the time course of L-alanine uptake into vesicles pre-loaded with concentrations of $\mathrm{MgCl}_{2}$ ranging from 0 to $5 \mathrm{mM}$ was measured. The $\mathrm{Na}^{+}$. stimulated uptake of L-alanine was inversely related to intravesicular $\mathrm{Mg}^{2+}$ concentrations (Fig. 3A). A similar inverse relationship was observed between intravesicular $\mathrm{Ca}^{2+}$ and $\mathrm{L}$-alanine uptake in vesicles pre-loaded with the same concentrations of $\mathrm{CaCl}_{2}$ (Fig. 3B). As previously shown in Figs. 1 and 2, $\mathrm{Na}^{+}$-independent
L-alanine uptake and equilibrium values were unaffected by intravesicular $\mathrm{Mg}^{2+}$ (Fig. 3A) and $\mathrm{Ca}^{2+}$ (Fig. 3B).

Although exogenous $\mathrm{CaCl}_{2}$ was not added to vesicle suspensions used as controls, these suspensions may contain micromolar levels of contaminating $\mathrm{Ca}^{2+}$, as reported by Vaandragen et al. [7]. To examine this issue, total calcium content of the suspension buffer and of the vesicle suspension solution was measured by atomic absorption. Unsupplemented suspension buffer and vesicle suspension solution were found to contain 1.0 $\mu \mathrm{M}$ calcium and $72.9 \pm 6.2 \mathrm{nmol}$ calcium per mg protein $(n=4)$, respectively, suggesting substantial binding of calcium to blLPM vesicles. Therefore, the chelator EGTA was used to lower intravesicular ionized calcium, and uptake of $\mathrm{L}$-alanine was measured under these conditions (Table I). Intravesicular EGTA $(0.2 \mathrm{mM})$ enhanced the initial rate of $\mathrm{Na}^{+}$-stimulated uptake of L-alanine by $17 \%$ (Table I), suggesting that micromolar levels of $\mathrm{Ca}^{2+}$ can influence $\mathrm{L}$-alanine uptake. Addition of excess $\mathrm{Ca}^{2+}(5 \mathrm{mM})$ overcame this enhancement and reduced uptake by $37 \%$ compared to control values. In the absence of EGTA, $\mathrm{Ca}^{2+}$ inhibited the initial rate of uptake by $33 \%$. The $\mathrm{Na}^{+}$-independent uptake of $\mathrm{L}$ alanine and the equilibrium values were unaffected by intravesicular $\mathrm{Ca}^{2+}$ or EGTA (Table I).

Initial rates of L-alanine uptake were similarly affected by intravesicular $\mathrm{Mg}^{2+}$ and/or EDTA. A 29\% increase in uptake was seen in vesicles pre-loaded with

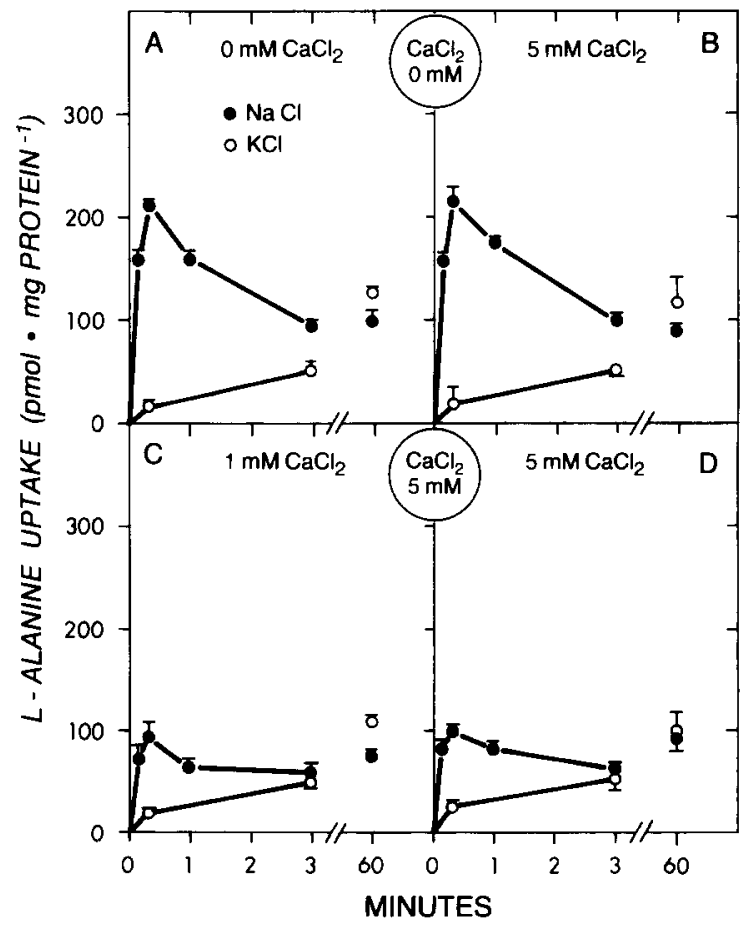

Fig. 2. Effects of intra- and extravesicular $\mathrm{Ca}^{2+}$ on L-alanine uptake by blLPM vesicles. The experiment illustrated in Fig. 1 was repeated with $\mathrm{CaCl}_{2}$ instead of $\mathrm{MgCl}_{2}$. See the legend to Fig. 1 for explanatory information. 


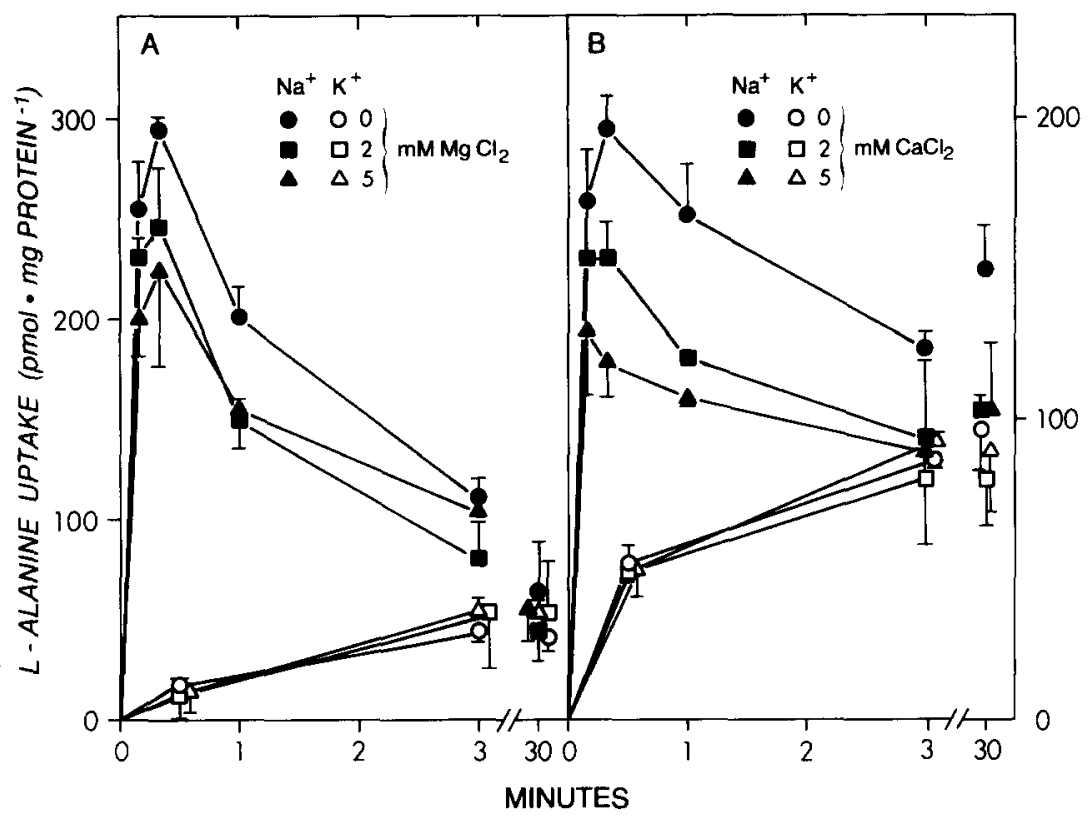

Fig. 3. Effects of increasing concentrations of intravesicular $\mathrm{Mg}^{2+}$ and $\mathrm{Ca}^{2+}$ on L-alanine uptake by blLPM vesicles. Vesicles were pre-loaded as

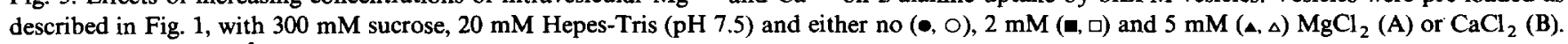
Uptake of $0.2 \mathrm{mM} \mathrm{L}-\left[{ }^{3} \mathrm{H}\right]$ alanine was measured at $25^{\circ} \mathrm{C}$ in an incubation solution containing $20 \mathrm{mM}$ Hepes-Tris (pH 7.5 ) and $100 \mathrm{mM}$ of either $\mathrm{NaCl}(\bullet, \omega, \Delta)$ or $\mathrm{KCl}(\mathrm{O}, \square, \Delta)$. Isoosmolarity of the incubation solution was maintained with sucrose. Results are shown for one representative experiment of three with each time point (mean \pm S.D.) performed in triplicate.

EDTA, while addition of excess $(5 \mathrm{mM}) \mathrm{Mg}^{2+}$ overcame this stimulation (Table II). Intravesicular $\mathrm{Mg}^{2+}$ alone inhibited uptake by $52 \%$. Equilibrium values and $\mathrm{Na}^{+}$-independent uptake were not significantly affected by intravesicular $\mathrm{Mg}^{2+}$ or EDTA (Table II).

To assess whether inhibition of $\mathrm{Na}^{+}$-stimulated Lalanine uptake was limited to $\mathrm{Mg}^{2+}$ and $\mathrm{Ca}^{2+}$ or was a property of divalent cations in general, the effects of

\section{TABLE I}

Effects of intravesicular EGTA on intial rates of L-alanine uptake by blLPM vesicles

Vesicles were pre-loaded with $300 \mathrm{mM}$ sucrose, $20 \mathrm{mM}$ Hepes-Tris (pH 7.5), and either no additions (control), $0.2 \mathrm{mM}$ EGTA, $5 \mathrm{mM}$ $\mathrm{CaCl}_{2}$, or both $0.2 \mathrm{mM}$ EGTA and $5 \mathrm{mM} \mathrm{CaCl}$. Uptake of $0.2 \mathrm{mM}$ $\mathrm{L}-\left[{ }^{3} \mathrm{H}\right]$ alanine by blLPM vesicles at $10 \mathrm{~s}$ and $60 \mathrm{~min}$ was measured at $25^{\circ} \mathrm{C}$ in an incubation solution containing $20 \mathrm{mM}$ Hepes-Tris ( $\mathrm{pH}$ 7.5 ), and either $100 \mathrm{mM} \mathrm{NaCl}$ or KCl. Data are presented as mean \pm S.D. of three experiments, each performed in triplicate. ${ }^{*}$ Significantly different from control values at $P<0.05$.

\begin{tabular}{llcc}
\hline Extravesicular & Intravesicular & \multicolumn{2}{c}{ pmol alanine per mg protein } \\
\cline { 3 - 4 } & & $10 \mathrm{~s}$ & $60 \mathrm{~min}$ \\
\hline $100 \mathrm{mM} \mathrm{NaCl}$ & control & $153 \pm 29$ & $92 \pm 15$ \\
& EGTA & $179 \pm 27 *$ & $98 \pm 23$ \\
& $\mathrm{CaCl}_{2}$ & $97 \pm 14$ & $95 \pm 22$ \\
& EGTA $+\mathrm{CaCl}_{2}$ & $103 \pm 19$ & $91 \pm 25$ \\
$100 \mathrm{mM} \mathrm{KCl}$ & control & $28 \pm 15$ & $84 \pm 10$ \\
& EGTA & $33 \pm 14$ & $89 \pm 24$ \\
& $\mathrm{CaCl}_{2}$ & $20 \pm 5$ & $79 \pm 16$ \\
& EGTA $+\mathrm{CaCl}_{2}$ & $26 \pm 11$ & $90 \pm 15$ \\
\hline
\end{tabular}

intravesicular $\mathrm{Co}^{2+}$ and $\mathrm{Mn}^{2+}$ were studied. Initial rates of L-alanine uptake were reduced by $54 \%$ and $49 \%$ in the presence of $5 \mathrm{mM}$ intravesicular $\mathrm{CoCl}_{2}$ and $\mathrm{MnCl}_{2}$, respectively (Table III). These cations did not affect $\mathrm{Na}^{+}$-independent L-alanine uptake.

It is possible that divalent cations may have indirectly inhibited $\mathrm{Na}^{+}$-coupled alanine transport by affecting $\mathrm{Na}^{+}$permeability, and therefore the concentration gradient which energizes $\mathrm{Na}^{+}$/alanine cotransport. Separate laboratories using intestinal brush-border membrane vesicles have associated inhibition of $\mathrm{Na}^{+}-$ coupled solute uptake by intravesicular divalent cations

\section{TABLE II}

Effects of intravesicular EDTA on initial rates of L-alanine uptake by bILPM vesicles

The experiment presented in Table I was repeated with $0.2 \mathrm{mM}$ EDTA and $5 \mathrm{mM} \mathrm{MgCl}$ instead of EGTA and $\mathrm{CaCl}_{2}$, respectively. See legend to Table I for details. ${ }^{*}$ Significantly different from control values at $P<0.05$.

\begin{tabular}{llcc}
\hline Extravesicular & Intravesicular & \multicolumn{2}{c}{ pmol alanine per mg protein } \\
\cline { 3 - 4 } & & $10 \mathrm{~s}$ & $60 \mathrm{~min}$ \\
\hline $100 \mathrm{mM} \mathrm{NaCl}$ & control & $153 \pm 22$ & $104 \pm 27$ \\
& EDTA & $197 \pm 37 *$ & $107 \pm 26$ \\
& $\mathrm{MgCl}_{2}$ & $73 \pm 10^{*}$ & $99 \pm 30$ \\
& EDTA $+\mathrm{MgCl}_{2}$ & $88 \pm 5^{*}$ & $119 \pm 8$ \\
$100 \mathrm{mM} \mathrm{KCl}$ & control & $25 \pm 6$ & $129 \pm 20$ \\
& EDTA & $32 \pm 3$ & $140 \pm 20^{*}$ \\
& $\mathrm{MgCl}_{2}$ & $33 \pm 15$ & $117 \pm 24$ \\
& EDTA $+\mathrm{MgCl}_{2}$ & $35 \pm 10$ & $127 \pm 35$ \\
\hline
\end{tabular}




\section{TABLE III}

Effects of intravesicular $\mathrm{Co}^{2+}$ and $\mathrm{Mn}^{2+}$ on L-alanine uptake by blLPM vesicles

Vesicles were pre-loaded with $300 \mathrm{mM}$ sucrose, $20 \mathrm{mM}$ Hepes-Tris ( $\mathrm{pH} 7.5$ ), and either no additions (control), $5 \mathrm{mM} \mathrm{CoCl}_{2}$, or $5 \mathrm{mM}$ $\mathrm{MnCl}_{2}$. Initial rates of uptake of $0.2 \mathrm{mM} \mathrm{L}-\left[{ }^{3} \mathrm{H}\right]$ alanine at $10 \mathrm{~s}$ were measured at $25^{\circ} \mathrm{C}$ in an incubation solution containing $20 \mathrm{mM}$ Hepes-Tris (pH 7.5), and either $100 \mathrm{mM} \mathrm{NaCl}$ or KCl. Isoosmolarity was maintained in the incubation solution using sucrose. Values are means \pm S.D. of three experiments, each performed in triplicate. ${ }^{*}$ Significantly different from control values at $P<0.05$.

\begin{tabular}{lccc}
\hline Salt gradients & \multicolumn{3}{c}{ pmol alanine/mg protein per $10 \mathrm{~s}$} \\
\cline { 2 - 4 } & Control & \multicolumn{1}{c}{$\mathrm{CoCl}_{2}$} & $\mathrm{MnCl}_{2}$ \\
\hline $100 \mathrm{mM} \mathrm{NaCl}$ & $232 \pm 53$ & $106 \pm 12^{*}$ & $119 \pm 45$ \\
$100 \mathrm{mM} \mathrm{KCl}$ & $41 \pm 24$ & $34 \pm 18$ & $44 \pm 46$ \\
\hline
\end{tabular}

with altered membrane permeability to $\mathrm{Na}^{+}[6,7]$. This possibility was tested by measuring uptake of $\mathrm{Na}^{+}$into vesicles preloaded with $\mathrm{Mg}^{2+}$ and $\mathrm{Ca}^{2+}$. It is important to note that $\mathrm{Na}^{+}$permeability was measured at two concentrations of ${ }^{22} \mathrm{Na}^{+}$, a roughly physiological concentration $(100 \mathrm{mM})$ and a low concentration $(1 \mathrm{mM})$ where more subtle effects on $\mathrm{Na}^{+}$entry should be detected. Uptake of ${ }^{22} \mathrm{Na}^{+}$was not altered in vesicles pre-loaded with $5 \mathrm{mM} \mathrm{MgCl}$ or $\mathrm{CaCl}_{2}$ at either $\mathrm{Na}^{+}$ concentration (Table IV).

The mechanism by which $\mathrm{Na}^{+}$-coupled L-alanine uptake was inhibited by divalent cations was further explored by comparing the kinetic parameters of $\mathrm{L}$-alanine uptake with and without intravesicular $5 \mathrm{mM} \mathrm{CaCl}_{2}$. In the presence of a $\mathrm{NaCl}$ gradient, initial rates of $\mathrm{L}$-alanine uptake at all concentrations tested ( 1 to $20 \mathrm{mM}$ ) were appreciably reduced by $\mathrm{Ca}^{2+}$, whereas uptake in the presence of a $\mathrm{KCl}$ gradient was unaffected (Fig. 4). A double-reciprocal plot of the net $\mathrm{Na}^{+}$-dependent component of L-alanine uptake revealed that the $K_{\mathrm{m}}$ for L-alanine was increased from $2.6 \pm 2.3$ to $3.8 \pm 0.6 \mathrm{mM}$, while the $V_{\max }$ was decreased from $2.2 \pm 1.0$ to $1.4 \pm 0.7$ $\mathrm{nmol} / \mathrm{mg}$ protein per $10 \mathrm{~s}$ by $\mathrm{Ca}^{2+}$ (Fig. 4 , inset).

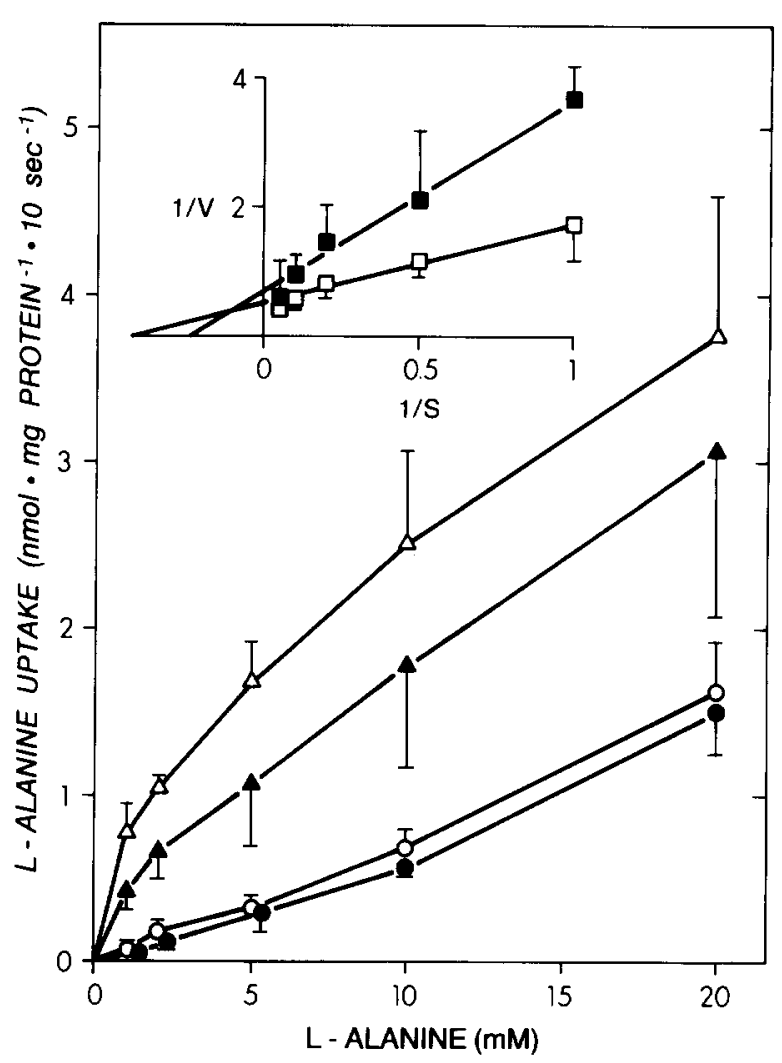

Fig. 4. Effect of intravesicular $\mathrm{Ca}^{2+}$ on concentration dependence of L-alanine uptake by bILPM vesicles. Vesicles were pre-loaded with $300 \mathrm{mM}$ sucrose, $20 \mathrm{mM}$ Hepes-Tris $(\mathrm{pH} 7.5)$ and either no $(O, \Delta)$ or 5 $\mathrm{mM} \mathrm{CaCl} 2(\bullet, \Delta)$. Initial rates $(10 \mathrm{~s})$ of uptake of 1 to $20 \mathrm{mM}$ L-alanine were measured at $25^{\circ} \mathrm{C}$ in an incubation solution containing $20 \mathrm{mM}$ Hepes-Tris (pH 7.5) and $100 \mathrm{mM}$ of either $\mathrm{NaCl}(\Delta, \Delta)$ or $\mathrm{KCl}(0, \bullet)$. The inset shows a double-reciprocal plot of the $\mathrm{Na}^{+}$ gradient-dependent transport system in the presence ( $\bullet$ ) or absence ( $\square$ ) of $\mathrm{Ca}^{2+}$. Results are expressed as mean \pm S.D. of four experiments each performed in triplicate.

However, the variability observed limits interpretation of how $\mathrm{Ca}^{2+}$ inhibited alanine uptake. This variability may in part be due to the difficulty of defining kinetic

\section{TABLE IV}

Effects of $\mathrm{Mg}^{2+}$ and $\mathrm{Ca}^{2+}$ on ${ }^{22} \mathrm{Na}$ uptake by blLPM vesicles

Vesicles were pre-loaded with $300 \mathrm{mM}$ sucrose, $50 \mathrm{mM}$ Hepes-Tris (pH 7.5), and either no additions (control), $5 \mathrm{mM} \mathrm{MgCl}$, or $5 \mathrm{mM} \mathrm{CaCl}_{2}$. Uptake of either $1 \mathrm{mM}$ or $100 \mathrm{mM}^{22} \mathrm{Na}$ was measured at $25^{\circ} \mathrm{C}$ in an incubation solution containing $300 \mathrm{mM}$ sucrose, $50 \mathrm{mM}$ Hepes-Tris (pH 7.5). Values are means \pm S.D. of three experiments, each performed in triplicate.

\begin{tabular}{|c|c|c|c|c|c|c|c|}
\hline \multirow[t]{2}{*}{ Extravesicular } & \multirow[t]{2}{*}{ Intravesicular } & \multicolumn{6}{|c|}{$\mathrm{nmol} \mathrm{Na}^{+}$per mg protein } \\
\hline & & $5 \mathrm{~s}$ & $10 \mathrm{~s}$ & $15 \mathrm{~s}$ & $60 \mathrm{~s}$ & $2 \min$ & $90 \mathrm{~min}$ \\
\hline \multirow[t]{3}{*}{$\overline{1 \mathrm{mM} \mathrm{Na}^{+}}$} & control & $0.19 \pm 0.20$ & $0.20 \pm 0.13$ & $0.33 \pm 0.20$ & $0.45 \pm 0.27$ & $0.60 \pm 0.27$ & $0.82 \pm 0.34$ \\
\hline & $5 \mathrm{mM} \mathrm{MgCl}_{2}$ & $0.19 \pm 0.12$ & $0.26 \pm 0.20$ & $0.41 \pm 0.29$ & $0.42 \pm 0.08$ & $0.51 \pm 0.17$ & $0.60 \pm 0.15$ \\
\hline & $5 \mathrm{mM} \mathrm{CaCl}_{2}$ & $0.22 \pm 0.24$ & $0.28 \pm 0.21$ & $0.32 \pm 0.20$ & $0.42 \pm 0.14$ & $0.51 \pm 0.13$ & $0.71 \pm 0.38$ \\
\hline \multirow[t]{3}{*}{$100 \mathrm{mM} \mathrm{Na}^{+}$} & control & $19.9 \pm 9.6$ & $26.4 \pm 9.2$ & $29.7 \pm 11.1$ & $52.2 \pm 17.7$ & $57.2 \pm 23.9$ & $73.2 \pm 18.0$ \\
\hline & $5 \mathrm{mM} \mathrm{MgCl}_{2}$ & $22.4 \pm 6.5$ & $26.3 \pm 8.4$ & $28.0 \pm 5.9$ & $56.9 \pm 19.4$ & $67.1 \pm 18.0$ & $65.0 \pm 13.4$ \\
\hline & $5 \mathrm{mM} \mathrm{CaCl}_{2}$ & $23.2 \pm 16.7$ & $25.5 \pm 12.1$ & $41.0 \pm 12.8$ & $56.9 \pm 13.7$ & $52.8 \pm 14.1$ & $77.8 \pm 21.4$ \\
\hline
\end{tabular}


parameters for a solute such as alanine which is transported via several membrane carriers [17].

\section{Discussion}

Alanine, an important oxidative and gluconeogenic substrate of the liver [18-20], is transported across liver sinusoidal membrane mainly by a $\mathrm{Na}^{+}$-coupled transport process $[10,17,21-24]$. In rat liver blLPM vesicles uptake of alanine in the presence of $\mathrm{Na}^{+}$is characterized by a distinctive overshoot above equilibrium values, and has served as a measure of the functional integrity of these membrane vesicles $[10,16]$. In the present study, intravesicular divalent cation concentrations of 2 to $5 \mathrm{mM}$ were found to inhibit alanine uptake in blLPM vesicles. Corkey et al. [25] estimated the cytosolic free $\mathrm{Mg}^{2+}$ level in hepatocytes to be $0.37 \mathrm{mM}$, and cytosolic free $\mathrm{Ca}^{2+}$ levels are generally in the nanomolar range. Although the concentrations of exogenous divalent cations added to the suspension solutions were greater than would be expected in vivo, stimulation of alanine uptake by the metal chelators EGTA and EDTA suggests that trace amounts of these cations in the suspension solutions may also influence uptake of alanine. This postulate is supported by the micromolar levels of total calcium detected in the unsupplemented suspension solutions and membrane suspensions. Likewise, Vaandrager et al. [7] observed greater glucose uptake in intestinal brush-border membrane vesicles in the presence of a $0.1 \mu \mathrm{M} \mathrm{Ca} /$ EGTA buffer compared to buffer with no additions. This was attributed to endogenous $\mathrm{Ca}^{2+}$ concentrations of 5 to $10 \mu \mathrm{M}$ in the absence of EGTA.

The mechanism by which divalent cations inhibit alanine transport is unclear. Intravesicular $\mathrm{Ca}^{2+}$ has been shown to inhibit $\mathrm{Na}^{+}$-coupled uptake of taurocholic acid, taurochenodeoxycholic acid, valine and glucose in intestinal brush border membrane vesicles $[6,7]$. Inhibition of uptake of these solutes was associated with changes in membrane permeabilities to ions. However, Vaandrager et al. [7] observed a general enhancement of anion and cation permeabilities, while Fondacaro and Madden [6] noted a decrease in permeability to $\mathrm{Na}^{+}$. These conflicting results argue against a direct relationship between divalent-cation induced changes in $\mathrm{Na}^{+}$permeability and uptake of these solutes. In intact human erythrocytes, the divalent cations $\mathrm{Ca}^{2+}, \mathrm{Mg}^{2+}, \mathrm{Co}^{2+}$ and $\mathrm{Mn}^{2+}$ have been shown to inhibit $\mathrm{Na}^{+} / \mathrm{K}^{+}$co-transport, and $\mathrm{Mg}^{2+}$ also inhibited $\mathrm{Na}^{+}$-dependent uptake of alanine and serine [26,27]. However, it was not established whether the decrease in flux of $\mathrm{Na}^{+}$was related to inhibition of uptake of these two amino acids. In the present study, intravesicular $\mathrm{Mg}^{2+}$ and $\mathrm{Ca}^{2+}$ did not alter the permeability of blLPM vesicles to $\mathrm{Na}^{+}$. Thus, the marked inhibition by divalent cations of alanine uptake was not a result of a change in $\mathrm{Na}^{+}$permeability.

It should be emphasized that only intravesicular divalent cations inhibited alanine uptake, irrespective of extravesicular concentrations. Because the blLPM vesicles are primarily oriented 'right-side-out', the inhibitory effect appears to be limited to the cytosolic surface of the cell membrane. Evidence for an intracellular effect of divalent cations on plasma membrane transport processes has also been reported for human erythrocytes. Garay [26] observed a decrease in $\mathrm{Na}^{+} / \mathrm{K}^{+}$ co-transport when intracellular, but not extracellular $\mathrm{Ca}^{2+}$ levels were elevated. Similarly, Vaandrager et al. [7] concluded that the site for inhibition of glucose uptake by $\mathrm{Ca}^{2+}$ was located at the inner surface of intestinal brush-border membrane vesicles.

There is a considerable body of evidence showing that $\mathrm{Ca}^{2+}[3,8,28]$, and even $\mathrm{Mg}^{2+}$ [3], can interact directly and indirectly with lipids to cause a decrease in membrane fluidity. Since changes in the lipid environment of transport proteins can affect their catalytic function [30], it is plausible that divalent cation inhibition of alanine uptake in blLPM vesicles was due to changes in membrane fluidity. Indeed, we have previously demonstrated that $\mathrm{Ca}^{2+}$ inhibition of taurocholate uptake in rat liver blLPM vesicles prepared as in this study was associated with a decrease in the fluidity of the membrane [8]. Direct interaction of divalent cations with membrane lipids probably occurs by binding to anionic sites on the polar head groups of phospholipids [2,31]. Since negatively charged phospholipids (e.g. phosphatidyl serine) are more abundant at the inner leaflet of sinusoidal membranes [32], binding to acidic phospholipids may explain why intravesicular, but not extravesicular $\mathrm{Ca}^{2+}$ and $\mathrm{Mg}^{2+}$ inhibited uptake of alanine by blLPM vesicles.

Divalent cations are also believed to cause a decrease in fluidity indirectly by activating membrane-bound enzymes (e.g. phospholipase C) which biochemically modify the lipid composition of the membrane bilayer [3]. Alternatively, binding of divalent cations at the interior of blLPM vesicles may have altered the surface charge. Since $\mathrm{Na}^{+}$-coupled uptake of alanine by blLPM vesicles is electrogenic, changes in the surface charge could have affected alanine transport. It is also possible that divalent cations inhibited uptake of alanine by interacting directly with the cytosolic domain of the carrier molecule for $\mathrm{Na}^{+}$/alanine co-transport. A similar mechanism has been proposed by Lauf [4] to explain inhibition by $\mathrm{Ca}^{2+}$ of $\mathrm{K}^{+} / \mathrm{Cl}^{-}$co-transport by sheep erythrocytes.

\section{Acknowledgements}

This study was supported in part by National Institute of Health Grants DK-39165 and ES-01248, and 
by an Environmental Toxicology Training Grant ES07026.

\section{References}

1 Phipps, D.A. (1976) Metals and Metabolism, Oxford Chemistry Series, Clarendon Press, Oxford.

2 Shlatz, L. and Marinetti, G.V. (1972) Biochim. Biophys. Acta 290, $70-83$.

3 Livingstone, C.J. and Schachter, D. (1980) Biochemistry 19, 48234827.

4 Lauf, P.K. (1985) Am. J. Physiol. 249, C271-278.

5 Dordick, R.S., Brierley, G.P. and Garlid, K.D. (1980) J. Biol. Chem. 255, 10299-10305.

6 Fondacaro, J.D. and Madden, T.B. (1984) Life Sci. 35, 1431-1438.

7 Vaandrager, A.B., Ploemacher, M.C. and De Jonge, H.R. (1986) Biochim. Biophys. Acta 856, 325-336.

8 Mills, P.R., Meier, P.J., Smith, D.J., Ballatori, N., Boyer, J.L. and Gordon, E.R. (1987) Hepatology 7, 61-66.

9 Meier, P.J., Sztul, E.S., Reuben, A. and Boyer, J.L. (1984) J. Cell. Biol. 98, 991-1000.

10 Meier, P.J., St. Meier-Abt, A., Barrett, C. and Boyer, J.L. (1984) J. Biol. Chem. 259, 10614-10622.

11 Moseley, R.H., Meier, P.J., Aronson, P.S. and Boyer, J.L. (1986) Am. J. Physiol. 250, G35-G43.

12 Scharschmidt, B.F., Keeffee, E.B., Blankenship, N.M. and Ockner, R.K. (1979) J. Lab. Clin. Med. 93, 790-799.

13 Orlowski, M. and Meister, A. (1963) Biochim. Biophys. Acta 73, 676-679.

14 Lowry, O.H., Rosebrough, N.J., Farr, A.L. and Randall, R.J. (1951) J. Biol. Chem. 193, 265-275.

15 Christensen, S. (1972) Atomic Absorption Newslett. 11, 51-52.
16 Ballatori, N., Moseley, R.H. and Boyer, J.L. (1986) J. Biol. Chem. 261, 6216-6221.

17 Sips, H.J., Van Amelsvoort, J.M.M. and Van Dam, K. (1980) Eur. J. Biochem. 105, 217-224.

18 Felig, P., Pozefsky, T., Marliss, E. and Cahill, G.F. (1970) Science Wash. DC 167, 1003-1004.

19 Friedrichs, D. and Schoner, W. (1974) Biochim. Biophys. Acta $343,341-355$.

20 Llorente, P.R., Marco, R. and Sols, A. (1970) Eur. J. Biochem. 13, $45-54$.

21 Edmondson, J.W., Lumeng, L. and Li, T.K. (1977) Biochem. Biophys. Res. Commun. 76, 751-757.

22 Edmondson, J.W., Lumeng, L. and Li, T.K. (1979) J. Biol. Chem. $254,1653-1658$.

23 Joseph, S.K., Bradford, N.M. and McGivan, J.D. (1978) Biochem. J. 105, 217-224.

24 Van Amelsvoort, J.M.M., Sips, H.J. and Van Dam, K. (1978) Biochem. J. 174, 1083-1086.

25 Corkey, B.E., Duszynski, J., Rich, T.L., Matschinsky, B. and Williamson, J.R. (1986) J. Biol. Chem. 261, 2567-2574.

26 Garay, R.P. (1982) Biochim. Biophys. Acta 688, 786-792.

27 Ellory, J.C., Flatman, P.W. and Stewart, G.W. (1983) J. Physiol. $340,1-17$

28 Storch, J., Schachter, D., Inoue, M. and Wolkoff, A.W. (1983) Biochim. Biophys. Acta 727, 209-212.

29 Gupte, S.S., Lane, L.K., Johnson, J.D., Wallick, E.T. and Schwarz, A. (1979) J. Biol. Chem. 254, 5099-5103.

30 Deuticke, B. and Haest, C.W.M. (1987) Annu. Rev. Biochem. 49, 221-235.

31 Gordon, L.M., Whetton, A.D., Rawal, S., Esgate, J.A. and Houslay, M.D. (1983) Biochim. Biophys. Acta 729, 104-114.

32 Higgins, J.A. and Evans, W.H. (1978) Biochem. J. 174, 563-567. 